\title{
Radiofrequency Identification Tagging in Ornamental Shrubs: An Application in Rose
}

\author{
Andrea Luvisi ${ }^{1,6}$, Alessandra Panattoni $^{1}$, Roberto Bandinelli ${ }^{2}$, \\ Enrico Rinaldelli ${ }^{3}$, Mario Pagano ${ }^{3}$, Barbara Gini ${ }^{4}$, \\ Giorgio Manzoni ${ }^{5}$, and Enrico Triolo ${ }^{1}$
}

AdDitional INDEX wORDs. RFID, traceability, pith

SUMMARY. Plant tagging using radiofrequency identification (RFID) microchips is attractive for ornamental shrubs, such as rose (Rosa spp.), due to their high market value, wide distribution, health certification system, and numerous uses. Differently from other woody species for which methods of microchip implantation have been tested, rose tagging requires the possibility of insertion within canes of less than $10 \mathrm{~mm}$ diameter, such as those typically found in the rose nursery setting. Moreover, the possibility of tagging after grafting without changing common plant production procedures and aesthetic value are important considerations. Toward this aim, a new method of microchip insertion was developed. To test its effects on roses, two cultivars were subjected to a tagging procedure, and histological observations of tissues around the microchip and growth analysis of plant canes were performed. Microchip implantation did not cause xylem necrosis in 8 - to 9-mm-diameter canes, but in lower diameter canes wilt of the lateral shoot and detriments in growth were observed compared with control plants. The tagged roses were tracked by a database developed for rose information, field log, and botanical sheet retrieval. Our findings suggest that rose plants can be safely tagged with a RFID microchip following suitable selection of cane calliper as early as the nursery phase without negative effects on plant appearance.

$\mathrm{R}$ FID technology has been introduced efficiently in animal identification systems (Artmann, 1999; Jansen and Eradus, 1999). RFID applications in the plant sector mainly involve food traceability, logistics, or harvest, with the microchip (TAG) externally attached to the plant or product (Ampatzidis et al., 2009; Jones et al., 2005; Purvis et al., 2006; Regattieri et al., 2007). However, in the last 5 years experimental trials focused on inserting TAGs within plants have been carried out on sweet orange (Citrus sinensis) on Carrizo citrange rootstock [C. sinensis $\times$ Poncirus trifoliata

The authors acknowledge support received from the nursery "Favilla Pietro Vivai" (Capannori, Italy) and from Fondazione Cassa di Risparmio di Lucca (Lucca, Italy).

${ }^{1}$ Department of Tree Science, Entomology, and Plant Pathology "G. Scaramuzzi," University of Pisa, Via del Borghetto, 80, 56124 Pisa, Italy

${ }^{2}$ Associazione Toscana Costitutori Viticoli (TOS.CO.VIT.), Via Vecchia di Marina, 6, 56010 San Piero a Grado, Pisa, Italy

${ }^{3}$ Department of Crop, Soil and Environmental Science, University of Florence, Viale delle Idee, 30, 50019 Sesto Fiorentino, Florence, Italy

${ }^{4}$ Vivai New Plants di Barbara Gini, Via Togliatti, 41, 56040 Cenaia, Pisa, Italy

${ }^{5}$ Centro di TeleGeomatica, University of Trieste, P.le Europa, 1, 34127 Trieste, Italy

${ }^{6}$ Corresponding author. E-mail: aluvisi@agr.unipi.it.
(Bowman, 2005)], cypress [Cupressus sempervirens (Centro Nazionale per l'Informatica nella Pubblica Amministrazione, 2006)], plane tree [Platanus hybrid (Institut National de la Recherche Agronomique, 2008)], grapevine (Vitis vinifera) on rootstock 1103 Paulsen [Vitis berlandieri $\times$ Vitis rupestris (Bandinelli et al., 2009; Triolo et al., 2007)], and other plants (Grieco et al., 2006). Keeping in mind plant histology and the dimension of organs, different techniques and TAG allocations have been proposed, and it seems that standardizing RFID tagging in plants is not possible.

In addition to the plants cited above, RFID tagging could also have interesting applications in ornamental shrubs such as roses due to their high market value, wide distribution, and relative phytosanitarian certification (Krczal, 1998). Some potential applications of RFID techniques could include procedures for tourism applications in parks or botanical gardens, similar to the museum context (Ghiani et al., 2009; Hsi and Faith, 2005), to avoid theft of important plants (Associated Press, 2008) or the monitoring of plant health status (Kumagai and Miller, 2006). Some advantages connected with implementation of RFID traceability systems in ornamental shrubs could be suggested by digital urban garden management for plant monitoring (Luchi et al., 2008; Vai, 2005), rationalizing protection treatments, and sampling. Moreover, as reported for grapevine (Luvisi et al., 2010b), RFID codes can be used for creating databases for data storage and consultation and to generate a "virtual garden" in which treatments performed, production, monitoring programs, global positioning system coordinates and other data are archived, simplifying the updating of field activity logs. Similar approaches to the use of RFID were suggested as possible implementations of future farm information management systems developed in the European Union (Sørensen et al., 2010).

To test RFID tagging procedures in ornamental shrubs, the rose was chosen for the present work. The tagging procedure took into account 1 ) the possibility of insertion within small diameter canes $(<10 \mathrm{~mm})$, such as those typically found in a rose nursery setting; 2) the possibility of inserting TAG after grafting, without changing common plant production procedures and minimizing tagging costs due to losses; and 3) maintenance of aesthetic value.

\section{Materials and methods}

Plants AND METHODS OF MICROCHIP IMPLANTATION. 'Queen Elizabeth' rose ('Charlotte Armstrong' $\times$ 'Floradora') and 'Dame de Coeur' rose ('Peace' $x$ 'Independence') were bud grafted in Nov. 2007 on multiflora

\begin{tabular}{llll}
\hline $\begin{array}{l}\text { Units } \\
\begin{array}{l}\text { To convert U.S. to SI, } \\
\text { multiply by }\end{array}\end{array}$ & U.S. unit & SI unit & $\begin{array}{l}\text { To convert SI to U.S., } \\
\text { multiply by }\end{array}$ \\
\hline 3.7854 & gal & $\mathrm{L}$ & 0.2642 \\
2.54 & inch(es) & $\mathrm{cm}$ & 0.3937 \\
25.4 & inch(es) & $\mathrm{mm}$ & 0.0394 \\
28.3495 & $\mathrm{oz}$ & $\mathrm{g}$ & 0.0353 \\
1 & $\mathrm{ppm}$ & $\mathrm{mg} \cdot \mathrm{L}^{-1}$ & 1 \\
$\left({ }^{\circ} \mathrm{F}-32\right) \div 1.8$ & ${ }^{\circ} \mathrm{F}$ & ${ }^{\circ} \mathrm{C}$ & $\left(1.8 \times{ }^{\circ} \mathrm{C}\right)+32$
\end{tabular}


rose (Rosa multiflora) (Favilla Pietro Vivai, Capannori, Italy). Plants were potted in a steam-sterilized peat/perlite mix (Agraria di Vita, Pescia, Italy) in 11L nursery container. Plants were maintained under greenhouse conditions to create a good-quality rose. Plants were watered as needed, alternating between water and water-soluble fertilizer mix applied at a rate of $20 \mathrm{~N}-2.2 \mathrm{P}-8.3 \mathrm{~K}$ (Cifo, Bologna, Italy) applied with a proportioned at a rate of $1500 \mathrm{mg} \cdot \mathrm{L}^{-1}$ nitrogen. No supplemental light was supplied. Maximum photosynthetic photon flux in the greenhouse was $900 \mu \mathrm{mol} \cdot \mathrm{m}^{-2} \cdot \mathrm{s}^{-1}$. In Nov. 2009, within each cultivar, two groups of plants were formed, selecting a 1-yearold cane on each scion. These selected canes were different in diameter (6-7 or $8-9 \mathrm{~mm})$, measured in correspondence to the second bud. Three types of treatments were tested: insertion procedure and TAG implantation (Rl), insertion procedure without TAG implantation (R2), and no insertion procedure (control). Within each diameter group and treatment, 30 plants were established. The tagging procedure proposed by Bandinelli et al. (2009) was modified to consider rose anatomy, histology, and farming techniques. Rl, R2, and control required the pruning of all canes of each cultivar, leaving two buds, just above the higher one $(5 \mathrm{~mm}$ higher). Direct drilling of the pith with a $2.5-\mathrm{mm}$ drill bit was then performed to a depth of $40 \mathrm{~mm}$ for R1 and R2 treatments, followed by microchip insertion in Rl-treated plants (Fig. 1), locating the TAG below the higher bud. The cut was protected by rubber solution (Kollant Arbokol, Venice, Italy). In procedure intention, the lateral shoot developed from the bud located above the TAG [Fig. 1, (L)] must not be completely pruned in the following years of cultivation. To consider the tissue status around TAGs, the lateral shoot had to be evaluated to guarantee a long-lasting activity of TAGs. In fact, this lateral shoot was considered essential to prevent wilt or damage of Rl-treated canes and subsequent loss of TAGs. The number of plants characterized by lateral shoot in wilted status out of the total plants expressed in percent was registered, excluding them from analysis.

To estimate the maintenance of signal penetration through rose wood with selected hardware over the years, rose cuttings of $50 \mathrm{~mm}$ diameter were used. TAGs were inserted at a depth of $10 \mathrm{~cm}$ by pith drilling into $25-\mathrm{cm}$-long fresh cuttings of 'Queen Elizabeth' rose and 'Dame de Coeur' rose of selected diameter. A reading test was immediately performed.

EleCtronic MATERIAL AND SOFTWARE. Transponder glass TAG RFIDs $(2.1 \mathrm{~mm}$ diameter and $12 \mathrm{~mm}$ long) were used, working at a frequency of $125 \mathrm{kHz}$ (InterMedia, Forlì, Italy). TAGs were electronically read by way of a 14-digit identification number using a flash card reader connected by Secure Digital (SD) slot to a palm-personal computer [palm-PC (Axim X51; Dell, Round Rock, TX)] able to identify the microchips from a distance of $10 \mathrm{~cm}$. Data recovery

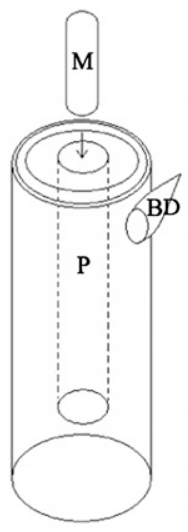

A

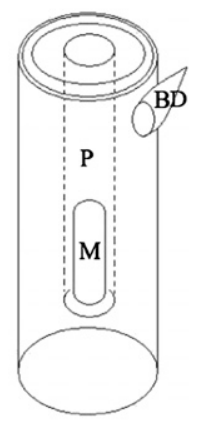

B

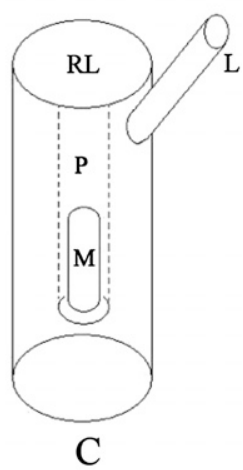

Fig. 1. Insertion procedure and microchip implantation (RI) in rose: (A) microchip (M) insertion after pruning and drilling of pith (P), (B) microchip positioning under higher bud (BD), (C) RI-treated cane and developed lateral shoot $(\mathrm{L})$ and rubber solution layer $(\mathrm{RL})$. was performed using a palm-PC containing a database specifically programmed using SprintDB Pro (KaioneSoft, Seoul, South Korea) for storing the data of each plant.

The RFID system was tested by evaluating TAG reliability, expressed in percent of reading failure, performing a microchip reading $90 \mathrm{~d}$ after insertion.

Database adaptation from Luvisi et al. (2010b) was developed to match TAGs with information datasheets that can be read and updated by users to manage the marked plants. The aim of the developed system was to permit access to datasheets by users involved in the flower production line-from flower grower to consumer-using the identification codes linked to TAGs. Datasheets and their access were designed considering privacy policies, with regard to each type of user. The online database was classified as a distributed rich Internet application system and was installed on a remote server, while flash technology was used for clients. The main software used was Java (Sun Microsystems, Santa Clara, CA) and Adobe Flex (Adobe Systems, San Jose, CA).

IMAGE ANALYSIS AND HISTOLOGICAL OBSERVATIONS. Measurements of the vascular tissue area (VTA), by image analysis and histological observations, were taken on samples collected at flower bud swelling phase (Apr. 2010), considering five plants per each diameter group and treatment.

Image analysis was performed on fresh trunk sections of RI- and R2treated canes collected in proximity of the microchip location, at about midlength of the microchip (height 0 ), $3 \mathrm{~mm}$ higher (height 3 ), and $3 \mathrm{~mm}$ lower (height -3 ). The functional VTA was calculated using software for image analysis (Cerri et al., 1993), measuring the total VTA and non-necrotic VTA, expressed in percent. The functional VTA was characterized by undamaged vessels and in which xylem rays were similar to control.

For histological observations, fresh longitudinal sections from Rland R2-treated canes were made considering the whole length of microchip, and fresh transversal sections were made in correspondence to the bud positioned above the TAG $(10 \mathrm{~mm}$ below distal cut). Sections were immediately observed under a light microscope (Leica, Wetzlar, Germany). In control, canes sections were taken at 

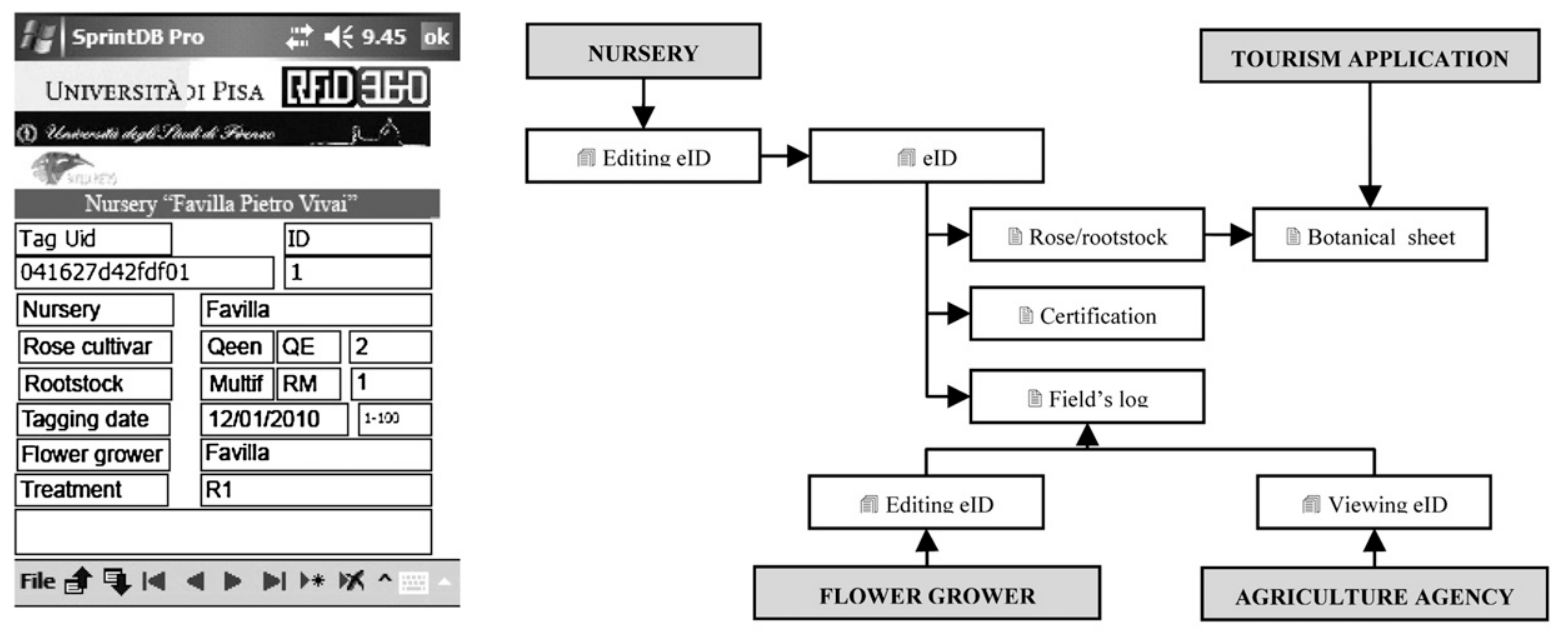

A

$\mathrm{B}$

Fig. 2. (A) Rose datasheet recorded in palm-personal computer database, (B) database schematization.

the same height of $\mathrm{Rl}$ - and $\mathrm{R} 2$-treated canes.

Shoot Assay. The mean relative growth rate [MRGR (in milligrams per day)] of 15 shoots per each diameter group and treatment was calculated using the equation reported by Kolb and Steiner (1990). One sampling period of $90 \mathrm{~d}$ was calculated from when shoots started growing. The dry weight was attained by drying the shoots overnight in an oven set at $100{ }^{\circ} \mathrm{C}$ and cooling the shoots in a closed plastic bag.

Data analysis. The effects of treatments (Rl, R2, and control) and interactions with cane diameters (6-7 or $8-9 \mathrm{~mm}$ ) were tested using SigmaPlot software (version 11; Systat Software, San Jose, CA). The software was used to perform two-way analysis of variance (ANOVA) in a random design and pairwise multiple comparisons on significant effects and interactions using the Holm-Sidak method. Data expressed in percent were converted in arcsin values. $P<0.05$ was considered to be significant.

\section{Results}

Database AND Microchip test. To access datasheets recorded in the palm-PC database, the TAG code of a marked plant is required. Codes can be read from a tagged plant or digitally entered into the search field of the database, and the datasheet is then shown (Fig. 2). The rose database was composed of four main folders

Table 1. Two-way factorial analysis of variance of functional vascular tissue area of 'Queen Elizabeth' and 'Dame de Coeur' rose, measured in treated canes (diameter 6-7 or 8-9 $\mathrm{mm}$ ) at midlength of the microchip (height 0 ), $3 \mathrm{~mm}$ lower (height -3 ), and $3 \mathrm{~mm}$ higher (height 3 ) and pairwise multiple comparison analysis with Holm-Sidak test.

\begin{tabular}{|c|c|c|c|c|c|c|}
\hline \multirow[b]{3}{*}{ Source of variation } & \multicolumn{3}{|c|}{ 'Queen Elizabeth' } & \multicolumn{3}{|c|}{ 'Dame de Coeur' } \\
\hline & $\overline{h t-3}$ & ht 0 & ht 3 & ht -3 & ht 0 & ht 3 \\
\hline & \multicolumn{6}{|c|}{ Probability } \\
\hline \multicolumn{7}{|l|}{ Main effect } \\
\hline Microchip insertion (A) & NS & $<0.001$ & $<0.001$ & NS & $<0.001$ & $<0.001$ \\
\hline Cane diameter $(\mathrm{B})$ & NS & $<0.001$ & $<0.001$ & NS & $<0.001$ & $<0.001$ \\
\hline \multicolumn{7}{|l|}{ Interactions } \\
\hline $\mathrm{A} \times \mathrm{B}$ & NS & $<0.001$ & $<0.001$ & NS & $<0.001$ & $<0.001$ \\
\hline \multicolumn{7}{|c|}{ Comparison for B within control } \\
\hline $6-7$ vs. $8-9 \mathrm{~mm}$ & - & NS & NS & - & NS & NS \\
\hline $\begin{array}{l}\text { Comparison for B within } \mathrm{R} \\
6-7 \text { vs. } 8-9 \mathrm{~mm}\end{array}$ & - & $<0.001$ & $<0.001$ & 一 & $<0.001$ & $<0.001$ \\
\hline $\begin{array}{l}\text { Comparison for } \mathrm{B} \text { within } \mathrm{R} \\
6-7 \text { vs. } 8-9 \mathrm{~mm}\end{array}$ & - & $<0.001$ & $<0.001$ & - & $<0.001$ & $<0.001$ \\
\hline \multicolumn{7}{|c|}{ Comparison for A within 6-7 $\mathrm{mm}$ cane diameter } \\
\hline Control vs. R2 & - & $<0.001$ & $<0.001$ & - & $<0.001$ & $<0.001$ \\
\hline Control vs. Rl & - & $<0.001$ & $<0.001$ & - & $<0.001$ & $<0.001$ \\
\hline Rl vs. R2 & - & NS & NS & - & NS & NS \\
\hline \multicolumn{7}{|c|}{ Comparison for A within $8-9 \mathrm{~mm}$ cane diameter } \\
\hline Control vs. R2 & - & NS & NS & - & NS & NS \\
\hline Control vs. Rl & - & NS & NS & - & NS & NS \\
\hline Rl vs. R2 & - & NS & NS & - & NS & NS \\
\hline
\end{tabular}

NSNonsignificant at $P>0.05$.

$\mathrm{Rl}=$ insertion procedure and microchip implantation, $\mathrm{R} 2=$ insertion procedure without microchip implantation, control $=$ no insertion procedure; $1 \mathrm{~mm}=0.0394$ inch .

(nursery, flower grower, rose cultivar, and rose rootstock) in which essential information was stored within specific fields. The creation of datasheets started with the selection of appropriate information from main folders, generating an electronic identity card (eID) for each plant. A counterpart database is available for web access with more in-depth data, especially with regard to botanical information. Four types of users were predicted (nurseryman, flower grower, agriculture agency, and tourist), and a privilege access system was developed to grant different uses. For example, a 
nurseryman can create an eID that refers to products, providing genetic and certification data; the flower farmer can edit specific fields relative to field $\operatorname{logs}$; a tourist can access botanical data; agriculture agencies or researchers can view fields relative to monitoring, health status, and treatments.

Microchip insertion did not compromise TAG reliability with $0 \%$ of reading failures considering each cultivar. The signal penetration was confirmed up to $50 \mathrm{~mm}$ of cane diameter.

IMAGE ANALYSIS AND HISTOLOGICAL OBSERVATIONS. No plants characterized by lateral shoot in wilted status were reported in diameter $8-9 \mathrm{~mm}$, while TAG insertion caused wilting in diameter 6-7 $\mathrm{mm}$ in 'Queen Elizabeth' rose $(28.9 \%)$ and 'Dame de Coeur' rose $(33.3 \%)$.

In non-wilted plants, analysis by two-way ANOVA (Table 1) revealed a nonsignificant effect of TAG insertion procedures and of cane diameters on functional VTA at height -3 in 'Queen Elizabeth' rose and 'Dame de Coeur' rose. As calculated by pairwise multiple comparison analysis, significant effects were measured in diameter 6-7 $\mathrm{mm}$ at height 0 and 3 when $\mathrm{Rl}$ or R2 treatments were performed, causing a reduction of functional VTA as compared with control in both cultivars (Fig. 3). No significant effects were measured in diameter $8-9 \mathrm{~mm}$.

Because no difference in histological observations were noted between culture, the following figures referring 'Queen Elizabeth' rose $\mathrm{Rl}$-treated canes (diameter 6-7 mm) showed damaged vessels $10 \mathrm{~mm}$ below the distal cut (Fig. 4B): xylem vessels were plugged, achieving complete occlusion of their lumen (browned wound parenchyma), and rays were fringed in proximity to pith, showing a different histological condition compared with control canes (Fig. 4A). In Rl-treated canes (diameter 8-9 mm), vessels were undamaged $10 \mathrm{~mm}$ below the distal cut (Fig. 4D) and xylem rays were similar to control canes (Fig. 4C), without deformation even in proximity to the microchip.

Longitudinal sections of $\mathrm{Rl}$ treated canes of diameter 6-7 $\mathrm{mm}$ showed fringed and browned tissues in proximity to pith (Fig. 5B), compared with control canes (Fig. 5A). With regard to diameter $8-9 \mathrm{~mm}$ canes, vessels in $\mathrm{Rl}$-treated canes were undamaged along their length

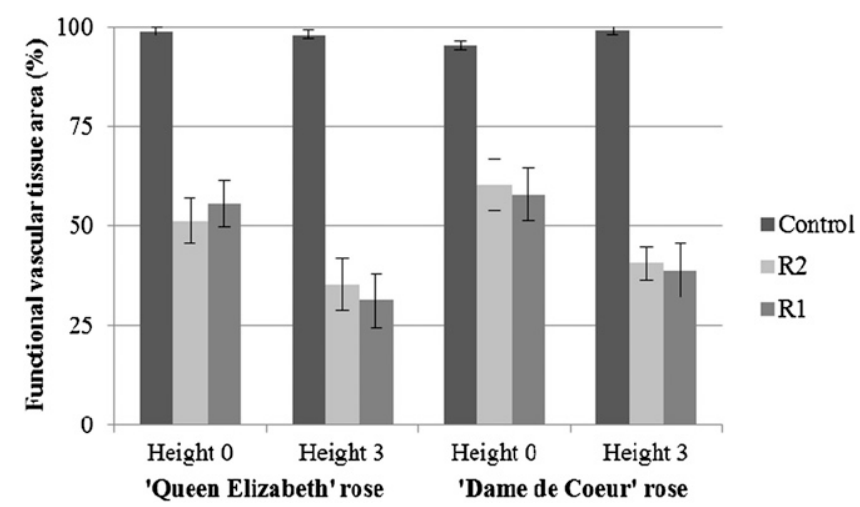

Fig. 3. Effects of implant procedure on 'Queen Elizabeth' and 'Dame de Coeur' rose on functional vascular tissue area measured at midlength of the microchip (height 0 ) and $3 \mathrm{~mm}$ higher (height 3 ) in 6 - to 7 - $\mathrm{mm}$-diameter canes. $\mathrm{Rl}=$ insertion procedure and microchip implantation, $\mathrm{R} 2$ = insertion procedure without microchip implantation, control $=$ no insertion procedure. Error bars represent $\pm S D ; 1 ~ m m=$ 0.0394 inch.
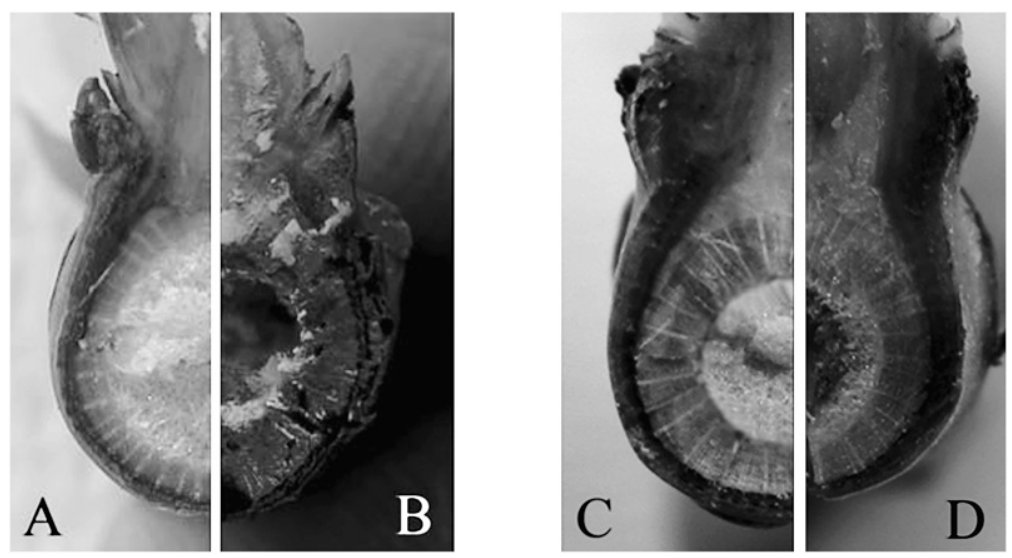

Fig. 4. Transversal sections of canes of 'Queen Elizabeth' rose, $10 \mathrm{~mm}$ below distal cut: (A) no insertion procedure in 6- to 7-mm-diameter cane, (B) insertion procedure and microchip implantation in 6- to 7-mm-diameter cane, $(\mathrm{C})$ no insertion procedure in 8- to 9-mm-diameter cane, and (D) insertion procedure and microchip implantation in 8- to 9 - $\mathrm{mm}$-diameter cane; $1 \mathrm{~mm}=0.0394$ inch.

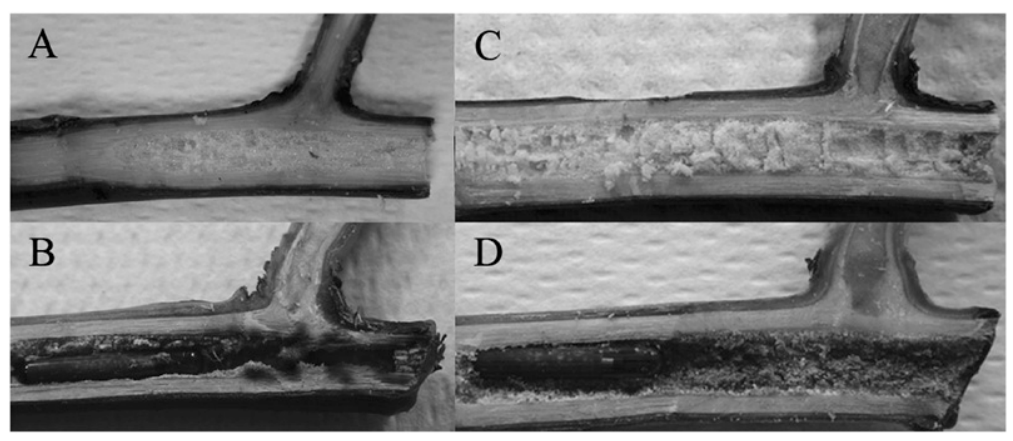

Fig. 5. Longitudinal sections of canes of 'Queen Elizabeth' rose: (A) no insertion procedure in 6- to 7-mm-diameter cane, $(B)$ insertion procedure and microchip implantation in 6- to 7-mm-diameter cane, $(\mathrm{C})$ no insertion procedure in 8- to 9-mm-diameter cane, and (D) insertion procedure and microchip implantation in 8- to 9 - $\mathrm{mm}$-diameter cane; $1 \mathrm{~mm}=0.0394$ inch. 
corresponding to microchip position (Fig. 5D) and xylem vessels were similar to control canes (Fig. 5C).

No differences were observed between $\mathrm{Rl}$ and $\mathrm{R} 2$ treatments performed in canes of the same diameter.

Assay of shoots. Analysis by two-way ANOVA (Table 2) revealed a significant effect of TAG insertion procedures and of cane diameters on MRGR in each cultivar. As calculated by pairwise multiple comparison analysis, significant effect were measured in diameter $6-7 \mathrm{~mm}$ when $\mathrm{Rl}$ or $\mathrm{R} 2$ treatments were performed, causing a reduction of MRGR as compared with control in 'Queen Elizabeth' rose and 'Dame de Coeur' rose (Fig. 6). Otherwise, no significant effects were measured in diameter $8-9 \mathrm{~mm}$.

\section{Discussion}

None of the RFID tagging methods in literature fit all the aims of the present work, and thus a new one had to be developed along with software for tracking plants. There were no differences between Rl-treated and R2-treated plants suggesting that proximity or contact of the glass microchip capsule to xylem did not cause changes in plant tissue unlike effects observed in grapevine (Luvisi et al., 2010a).

The responses to treatments were analogous in both cultivars. Histological observations, corroborated by image analysis, revealed that, compared with the plants which did not undergo the insertion procedure, 6to 7 -mm-diameter plants in the other two treatments ( $\mathrm{Rl}$ and R2) showed necrosis and occlusions on vascular tissue and wilted lateral shoots were recorded in more than $28 \%$ of treated canes with a significant decrease in MRGR in surviving shoots, compared with untreated plants. R1- or R2treated canes in $8-9 \mathrm{~mm}$ diameter did not show reduction in functional VTA, wilt of lateral shoot, or detrimental growth compared with control canes. As reported for large diameter plants such as cypress (Battezzati et al., 2006), the insertion of tags after trunk drilling did not cause wood alterations.

Negative effects can be linked to irreversible damage of xylem directly caused by drilling. Wounding is known to result in occlusion of the xylem conduits (Chattaway, 1948; Davies et al., 1981; Zimmermann, 1983), and severe plugging of vessels can lead to rose collapse (De Stigter and

Table 2. Two-way factorial analysis of variance of shoot biomasses of treated canes (diameter 6-7 or 8-9 mm) of 'Queen Elizabeth' and 'Dame de Coeur' rose as mean relative growth rate (MRGR) with one sampling period of $90 \mathrm{~d}$ calculated from start of shoot growth and pairwise multiple comparison analysis with Holm-Sidak test.

\begin{tabular}{|c|c|c|c|c|c|c|}
\hline \multirow[b]{2}{*}{ Source of variation } & \multicolumn{3}{|c|}{ 'Queen Elizabeth' } & \multicolumn{3}{|c|}{ 'Dame de Coeur' } \\
\hline & $S^{\mathbf{z}}$ & $\mathbf{d f}^{\mathbf{z}}$ & $P$ & SS & df & $P$ \\
\hline \multicolumn{7}{|l|}{ Main effect } \\
\hline Microchip insertion (A) & 164 & 2 & $<0.001$ & 161 & 2 & $<0.001$ \\
\hline Cane diameter $(\mathrm{B})$ & 2849 & 1 & $<0.001$ & 2250 & 1 & $<0.001$ \\
\hline \multicolumn{7}{|l|}{ Interactions } \\
\hline $\mathrm{A} \times \mathrm{B}$ & 155 & 2 & $<0.001$ & 244 & 2 & $<0.001$ \\
\hline Residual & 576 & 84 & & 238 & 84 & \\
\hline Comparison for factors & $\mathrm{DM}^{\mathrm{z}}$ & $t^{2}$ & $P$ & DM & $t$ & $P$ \\
\hline \multicolumn{7}{|c|}{ Comparison for $\mathrm{B}$ within control } \\
\hline $6-7$ vs. $8-9 \mathrm{~mm}$ & 7.589 & 7.936 & $<0.001$ & 5.356 & 8.708 & $<0.001$ \\
\hline \multicolumn{7}{|l|}{ Comparison for $\mathrm{B}$ within $\mathrm{R} 2$} \\
\hline $6-7$ vs. $8-9 \mathrm{~mm}$ & 12.558 & 13.177 & $<0.001$ & 12.009 & 19.674 & $<0.001$ \\
\hline \multicolumn{7}{|l|}{ Comparison for $\mathrm{B}$ within $\mathrm{Rl}$} \\
\hline $6-7$ vs. $8-9 \mathrm{~mm}$ & 13.572 & 14.194 & $<0.001$ & 12.550 & 20.406 & $<0.001$ \\
\hline \multicolumn{7}{|c|}{ Comparison for A within 6-7 $\mathrm{mm}$ cane diameter } \\
\hline Control vs. R2 & 5.812 & 6.066 & $<0.001$ & 6.401 & 10.406 & $<0.001$ \\
\hline Control vs. Rl & 4.902 & 5.124 & $<0.001$ & 6.198 & 10.081 & $<0.001$ \\
\hline Rl vs. R2 & 0.886 & 0.941 & NS & 0.204 & 0.325 & NS \\
\hline \multicolumn{7}{|c|}{ Comparison for A within $8-9 \mathrm{~mm}$ cane diameter } \\
\hline Control vs. R2 & 1.872 & 1.958 & NS & 0.994 & 1.617 & NS \\
\hline Control vs. Rl & 1.083 & 1.133 & NS & 0.650 & 1.057 & NS \\
\hline Rl vs. R2 & 0.789 & 0.825 & NS & 0.344 & 0.560 & NS \\
\hline
\end{tabular}

${ }^{2} \mathrm{SS}=$ sum of square, $\mathrm{df}=$ degrees of freedom, $\mathrm{DM}=$ difference of means, $t=t$-value.

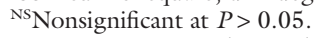

$\mathrm{R} 1=$ insertion procedure and microchip implantation, $\mathrm{R} 2=$ insertion procedure without microchip implantation, control $=$ no insertion procedure; $1 \mathrm{~mm}=0.0394$ inch.

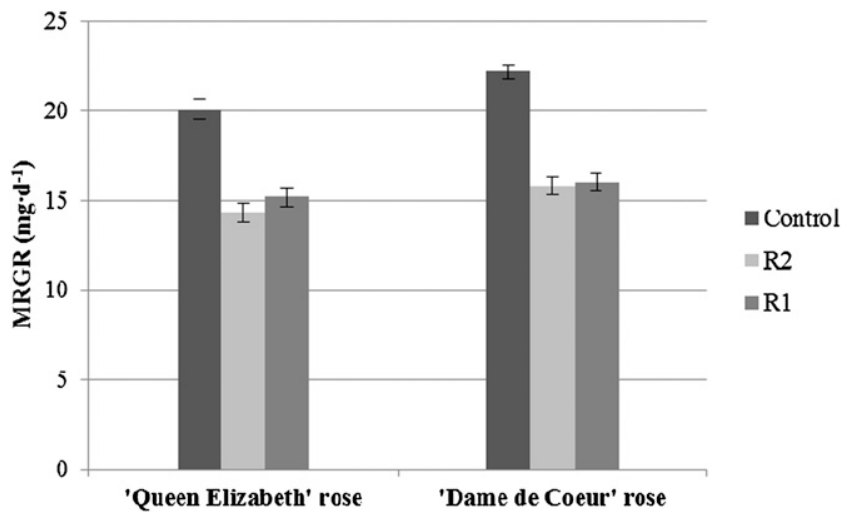

Fig. 6. Effects of implant procedure on 'Queen Elizabeth' and 'Dame de Coeur' rose on mean relative growth rate (MRGR), with one sampling period of $90 \mathrm{~d}$ calculated from start of shoot growth in 6-to 7 - $\mathrm{mm}$-diameter canes. $\mathrm{Rl}=$ insertion procedure and microchip implantation, $\mathrm{R} 2$ = insertion procedure without microchip implantation, control $=$ no insertion procedure. Error bars represent $\pm S D ; 1 \mathrm{~mm}=$ 0.0394 inch; $1 \mathrm{mg}=3.5274 \times 10^{-5} \mathrm{oz}$.

Broekhuysen, 1986). Thus, the selection of suitable cane diameter was essential to obtain no effects in tagged rose, reducing the diameter limit for rose to 8-9 mm compared with $10 \mathrm{~mm}$ for sweet orange (Bowman, 2005) and 15 $\mathrm{mm}$ for grapevine (Luvisi et al., 2010a).
Microchip insertion did not compromise the reliability of TAGs, and signal penetration through rose wood was confirmed in cane of up to $50 \mathrm{~mm}$ diameter. As reported by Bowman (2005), the distance for reading microchips can be increased using more 
powerful scanners, permitting TAG reading for 10 years or more in most of woody plant species.

In conclusion, RFID TAGs can be safely inserted in rose canes of a certain size $(8-9 \mathrm{~mm})$ without necessitating a change in plant production procedures or their appearance. The proposed database can trace TAGs and the associated plants during each phase of their life, from nursery to educational or touristic uses.

\section{Literature cited}

Ampatzidis, Y.Z., S.G. Vougioukas, D.D. Bochtis, and C.A. Tsatsarelis. 2009. A yield mapping system for hand-harvested fruits based on RFID and GPS location technologies: Field testing. Precis. Agr. 10: 63-72.

Artmann, R. 1999. Electronic identification systems: State of the art and their further development. Comput. Electron. Agr. 24:5-26.

Associated Press. 2008. Theft deterrence for an Arizona icon. New York Times 12 Oct. 2008, p. 39.

Bandinelli, R., E. Triolo, A. Luvisi, M. Pagano, B. Gini, and E. Rinaldelli. 2009. Employment of radiofrequency technology (RFID) in grapevine nursery traceability. Adv. Hort. Sci. 23:75-80.

Battezzati, L., G. Miragliotta, and A. Perego. 2006. RFID alla prova dei fatti. 8 Oct. 2010.<http://www.rdlog.it/doc/ Report_RFId_2006.pdf>.

Bowman, K.D. 2005. Identification of woody plants with implanted microchips. HortTechnology 15:352-354.

Centro Nazionale per l'Informatica nella Pubblica Amministrazione. 2006. Le tecnologie RFID nella pubblica amministrazione italiana: Temi di ricerca e sperimentazione. 8 Oct. 2010. <http://www. cnipa.gov.it/site/_files/RFID_Relazione_ stage_SABENE_v2.pdf $>$.

Cerri, S., A. Panattoni, and E. Triolo. 1993. Studio, progetto e sperimentazione di una procedura semiautomatica per l'analisi di alterazioni del legno in barba- telle di vite. Consiglio Nazionale Ricerche Nota Interna B4-25:1-24.

Chattaway, M.M. 1948. The development of tyloses and secretion of gum in heartwood formation. Austral. J. Sci. Ser. B. Biol. Sci. 2:227-240.

Davies, F.S., C.E. Munoz, and W.B. Sherman. 1981. Opening and vase life extension of peach flowers on detached shoots with sucrose and ethanol. J. Amer. Soc. Hort. Sci. 106:809-813.

De Stigter, H.C.M. and A.G.M. Broekhuysen. 1986. Experimentally induced plugging of cut-rose xylem by particulate or macromolecular matter. Acta Hort. 181: $365-370$.

Ghiani, G., F. Paterno, C. Santoro, and L.D. Spano. 2009. UbiCicero: A location-aware, multi-device museum guide. Interact. Comput. 21:288-303.

Grieco, P.D., S. Mendoliera, V. Castoro, V. Vitelli, F. Cellini, A. Agnello, F. Buccigrossi, and G. Vigo. 2006. La tecnologia RFID per la tracciabilità e la certificazione delle produzioni vivaistiche. Rivista di Frutticoltura 10:60-70.

Hsi, S. and H. Faith. 2005. RFID enhances visitors' museum experience at the exploratorium. Commun. Assn. Computing Machinery 48:60-65.

Institut National de la Recherche Agronomique. 2008. Platanor ${ }^{\circledR}$ Vallis clausa, a plane tree variety resistant to canker stain. 8 Oct. 2010. <http://www.international. inra.fr/press/platanor_r_vallis_clausa >.

Jansen, M.B. and W. Eradus. 1999. Future developments on devices for animal radiofrequency identification. Comput. Electron. Agr. 24:109-117.

Jones, P., C. Clarke-Hill, D. Comfort, D. Hillier, and P. Shears. 2005. Radio frequency identification and food retailing in the UK. Brit. Food J. 107:356-360.

Kolb, T.E. and K.C. Steiner. 1990. Growth and biomass partitioning response of northern red oak genotypes to shading and grass root competition. For. Sci. 36:293-303.

Krczal, G. 1998. Virus certification of ornamental plants: The European strategy, p. 227-287. In: A. Hadidi, R.K.
Khetarpal, and H. Koganezawa (eds.). Plant virus disease control. APS Press, St. Paul, MN.

Kumagai, M.H. and P. Miller. 2006. Development of electronic barcodes for use in plant pathology and functional genomica. Plant Mol. Biol. 61:515-523.

Luchi, N., M. Vannuccini, T. Panzavolta, R. Tiberi, M. Feducci, F. Salbitano, M. Giachini, L. Zocco Pisana, and P. Capretti. 2008. Censimento e indicazioni gestionali contro le avversità delle alberature dell'Opera delle Mura di Lucca. Forest 5:253261.

Luvisi, A., A. Panattoni, R. Bandinelli, E. Rinaldelli, M. Pagano, B. Gini, and E. Triolo. 2010a. RFID microchip internal implants: Effects on grapevine histology. Sci. Hort. 124:349-353.

Luvisi, A., E. Triolo, E. Rinaldelli, R. Bandinelli, M. Pagano, and B. Gini. 2010b. Radiofrequency applications in grapevine: From vineyard to web. Comput. Electron. Agr. 70:256-259.

Purvis, A.C., W.B. McGlasson, and S. Kanlayanarat. 2006. Progressive challenges in horticultural supply chains: Some future challenges. Acta Hort. 712: 39-49.

Regattieri, A., M. Gamberi, and R. Manzini. 2007. Traceability of food products: General framework and experimental evidence. J. Food Eng. 81:347-356.

Sørensen, C.G., S. Fountasb, E. Nashf, L. Pesonend, D. Bochtisa, S.M. Pedersene, B. Bassoc, and S.B. Blackmoreg. 2010. Conceptual model of a future farm management information system. Comput. Electron. Agr. 72:37-47.

Triolo, E., A. Luvisi, R. Bandinelli, E. Rinaldelli, and M. Pagano. 2007. RFID technology for improving traceability in grapevine nursery sector. J. Plant Pathol. 89:63-64.

Vai, N. 2005. Un sistema di mappatura dei platani colpiti dal cancro colorato. Alberi e territorio 2:34-37.

Zimmermann, M.H. 1983. Xylem structure and the ascent of sap. SpringerVerlag, Berlin. 